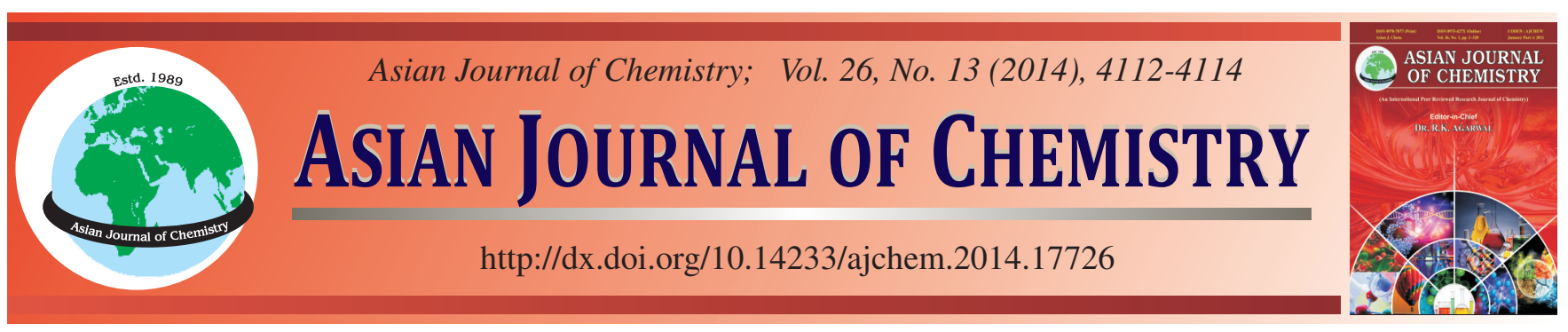

\title{
Microwave-Assisted Synthesis of Pd-MWCNT/TiO 2 Catalysts and its Application in the Photodegradation of Reactive Black B $\dagger$
}

\author{
Shu Ye, Kefayat Ullah, Lei Zhu, Sun Bok Jo and Won-Chun OH ${ }^{*}$
}

Department of Advanced Materials Science \& Engineering, Hanseo University, Chungnam 356-706, Republic of Korea

*Corresponding author: Fax: +82 41 6883352; Tel: +82 41 6601337; E-mail: wc_oh@ @anseo.ac.kr

MWCNT-TiO 2 and Pd-MWCNT/TiO 2 composites were prepared via a controlled and energy efficient microwave assisted method and their high photocatalytic activity was evaluated by the degradation of reactive black B solutions (RBB) under visible light. The surface structure, crystal phase and elemental identification of these composites were characterized by SEM, TEM, XRD, EDX and UV-visible, respectively. The degradation of reactive black-B solution was determined using UV-visible spectrophotometry. These as-prepared photocatalysis were used for $\mathrm{H}_{2}$ evolution under visible light irradiation. An increase in photocatalytic activity was observed and it may attribute to the increase of the photo-absorption effect by the MWCNT and the cooperative effect of Pd element.

Keywords: Microwave, MWCNT, Visible light, UV-visible, Pd, TEM, Reactive black-B.

\section{INTRODUCTION}

Photocatalytic processe is a promising class of advanced oxidation technologies used for environmental remediation ${ }^{1}$. $\mathrm{TiO}_{2}$ has excellent photocatalytic properties with applications in medicine, buildings and environmental remediation ${ }^{2,3} \cdot \mathrm{TiO}_{2}$ has been studied intensively as a photocatalyst for the complete degradation of organic pollutants ${ }^{3-5}$ because it is easily available, nontoxic, low cost and chemically stable. However, $\mathrm{TiO}_{2}$ has some shortcomings preventing its widespread applications. $\mathrm{TiO}_{2}$ is difficult to separate from aqueous phase and has relatively low quantum yield due to the rapid recombination of electron/hole pairs and can only used under ultraviolet (UV) light.

In this study, we combined Pd nanoparticles on an MWCNT matrix to design an effective catalyst. To improve the catalysis activity, $\mathrm{TiO}_{2}, \mathrm{MWCNT} / \mathrm{TiO}_{2}$ and $\mathrm{Pd}-\mathrm{MWCNT} / \mathrm{TiO}_{2}$ as composites were prepared by the microwave-assisted method. The prepared catalysts were characterized by XRD, EDX, SEM and TEM techniques. The catalytic efficiency of the Pd-MWCNT/ $\mathrm{TiO}_{2}$ composite was evaluated by the photo degradation of commercial industrial dye (reactive black B) under visible light.

\section{EXPERIMENTAL}

Multiwalled carbon nanotubes are very stable. They need to be treated with strong acids to introduce active functional groups on their surface. In this experiment, 6.0 g MCPBA was suspended in $200 \mathrm{~mL}$ of benzene as a solvent. Then $3 \mathrm{~g}$ of MWCNTs powder was put into the solution and the mixture was treated by magnetic stirring for $6 \mathrm{~h}$ at $353 \mathrm{~K}$. The resultant solution was filtered and continuously washed with deionized water and ethanol 5 times. The sample was dried at $393 \mathrm{~K}$ and fully milled.

One beaker containing $20 \mathrm{~mL}$ of ethanol $(95.0 \%)$ was prepared; $2 \mathrm{~mL}$ of TNB was then added to the solution, followed by magnetic stirring for $5 \mathrm{~min}$; $10 \mathrm{~mL}$ distilled water was added dropwise to the solution with constant stirring. From the above, after added $10 \mathrm{~mL}$ distilled water into the TNB $(2 \mathrm{~mL})$ and ethanol $(20 \mathrm{~mL})$ solution, $50 \mathrm{~mL}$ volume fraction of $5 \%$ hydrochloric acid solution; $0.5 \mathrm{~g}$ as-prepared oxidized MWCNT powder and $0.5 \mathrm{~g} \mathrm{PdCl}_{2}$ yellow powder were added into the solution, respectively with microwave irradiation for $20 \mathrm{~min}$ in a domestic microwave oven for $4 \mathrm{~h}$. After that, use the same process to wash the black solution 5 times as above, dried at $373 \mathrm{~K}$. Then heat treated at $773 \mathrm{~K}$ for $1 \mathrm{~h}$. This sample was named Pd-MWCNT/TiO 2 . (Fig. 1).

Measurement of photocatalytic activities: The photocatalytic activities of the $\mathrm{MWCNT} / \mathrm{TiO}_{2}$ and $\mathrm{Pd}-\mathrm{MWCNT} / \mathrm{TiO}_{2}$ were determined by the decomposition of reactive black-B in aqueous solution under visible light. The catalysts $(0.05 \mathrm{~g})$ were suspended in $100 \mathrm{~mL}$ of reactive black-B solution with a concentration of $0.002 \mathrm{~g} / \mathrm{L}$ in a glass vessel. Prior to irradiation, 


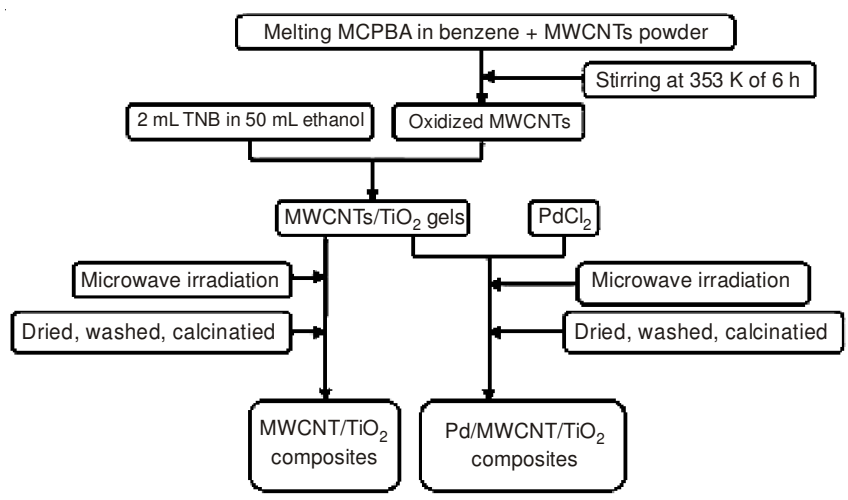

Fig. 1. Procedure for the preparation of $\mathrm{MWCNT} / \mathrm{TiO}_{2}$ and $\mathrm{Pd}-\mathrm{CNT} / \mathrm{TiO}_{2}$ composites

the suspensions were magnetically stirred in the dark for $0.5 \mathrm{~h}$ to ensure the establishment of an adsorption/desorption equilibrium among the photocatalyst, reactive black-B and atmospheric oxygen, which was hereafter considered as the initial concentration. Photocatalytic degradation was tested using the $\mathrm{MWCNT} / \mathrm{TiO}_{2}$ and $\mathrm{Pd}-\mathrm{MWCNT} / \mathrm{TiO}_{2}$ catalysts under visible light irradiation. The reactions were carried out in an open cylindrical stainless glass vessel. The light irradiation of the reactor was done for 30, 60, 90 and $120 \mathrm{~min}$ and the removal of the dispersed powders through centrifuge. The clean transparent solution was analyzed using a UV-visible spectrophotometer. The spectra $(450-700 \mathrm{~nm})$ for each sample were recorded and the absorbance was determined at the characteristic wavelength of $597 \mathrm{~nm}$. As the catalytic properties of $\mathrm{Pd}-\mathrm{MWCNT} / \mathrm{TiO}_{2}$ composition absorption and degradation the black colour of the solution faded gradually with time. For the recycling, $\mathrm{MWCNT} \mathrm{TiO}_{2}$ and $\mathrm{Pd}-\mathrm{MWCNT} / \mathrm{TiO}_{2}$ photocatalysts were recycled three times.

\section{RESULTS AND DISCUSSION}

SEM and EDX analysis: The X-ray diffraction (XRD) patterns of Anatase $\mathrm{TiO}_{2}, \mathrm{MWCNT} / \mathrm{TiO}_{2}$ and $\mathrm{Pd}-\mathrm{MWCNT} / \mathrm{TiO}_{2}$ composites are shown in Fig. 2. It could be confirmed that the $\mathrm{TiO}_{2}$ in the as-prepared photocatalysts is anatase-phase. For these three samples, (101), (004), (200), (105), (211) and (204) crystal planes are originated from the anatase $\mathrm{TiO}_{2}$ phase while (111), (112), (121), (103), (031), (200), (213) and (134) crystal planes are originated from the Pd element phase ${ }^{17}$. After refinement, the cell constants are calculated to $\mathrm{a}=4.2261 \AA$, b = $6.9238 \AA, c=7.8547 \AA$ (JCPDS card No. 14-0072). No impurity phase is detected. The broadening of these diffraction peaks indicates that the sample is nanosized. The crystalline size of the sample is estimated to be $15 \mathrm{~nm}$ from the Scherrer equation.

Moreover, these nanocomposite particles were further characterized by EDX which showed the expected peaks for $\mathrm{Pd}$ element, as well as the peak of $\mathrm{Ti}$ due to $\mathrm{TiO}_{2}$ and other impure elements such as $\mathrm{Cu}$ and $\mathrm{Zn}$ are also existed which might get from the experimental process. he elemental contents of $\mathrm{MWCNT} / \mathrm{TiO}_{2}$ and $\mathrm{Pd}-\mathrm{MWCNT} / \mathrm{TiO}_{2}$ composite photocatalysts were listed in Table-1.

TEM analysis: The TEM images of the $\mathrm{MWCNT} / \mathrm{TiO}_{2}$ and $\mathrm{Pd}-\mathrm{MWCNT} / \mathrm{TiO}_{2}$ composites are shown in Fig. 3. From Fig. 3(a) and (b), it could be observed that the $\mathrm{TiO}_{2}$ particles were well dispersed on the surface of MWCNT with a few

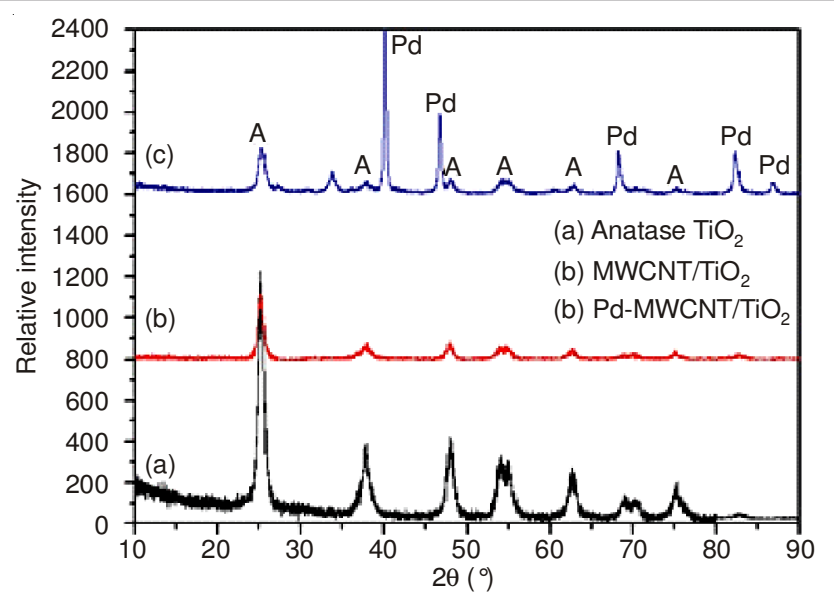

Fig. 2. XRD patterns of pure anatase $\mathrm{TiO}_{2}$ (a), $\mathrm{MWCNT} / \mathrm{TiO}{ }_{2}$ (b) and Pd$\mathrm{MWCNT} / \mathrm{TiO}_{2}(\mathrm{c})$

\begin{tabular}{lccccc}
\multicolumn{6}{c}{ TABLE-1 } \\
EDX ELEMENTAL MICROANALYSIS (wt \%) OF \\
MWCNT/TiO \\
MWND Pd-MWCNT/TiO \\
Sample COMPOSITES \\
\cline { 2 - 7 }
\end{tabular}
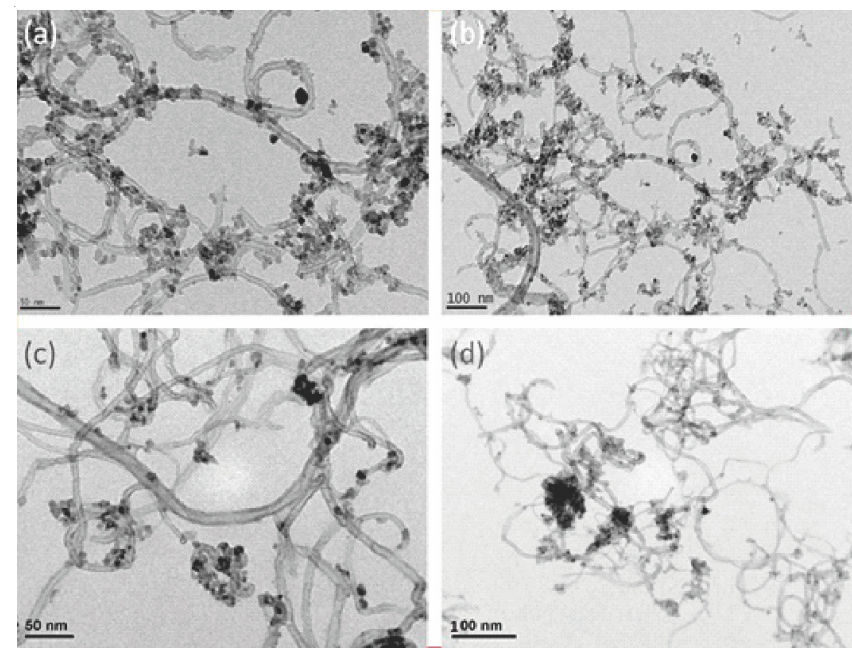

Fig. 3. TEM images of composite photocataysts: (a) and (b) MWCNT/ $\mathrm{TiO}_{2}$, (c) and (b) Pd- MWCNT/TiO

$\mathrm{TiO}_{2}$ particles agglomerated together due to the formation of large grains. The difference in the particle size distribution between the images in Fig. 3(c) and (d) was clearly observed. A few regular black dots were observed, which correspond to $\mathrm{Pd}$ particles. The mean size of the Pd nanoparticles was approximately $8-10 \mathrm{~nm}$, as obtained from the TEM image. In other words, the Pd particles with a small size were attached uniformly to the surface of the MWCNT. The size of the $\mathrm{TiO}_{2}$ particles was $10-20 \mathrm{~nm}$ and they were distributed uniformly on the surface of the MWCNT. A generally precipitate-free and smooth interface was observed among the $\mathrm{Pd}, \mathrm{TiO}_{2}$ and the MWCNT matrix.

\section{Degradation procedure}

Adsorption ability: To obtain an accurate degradation data of the MWCNT/TiO ${ }_{2}$ and Pd-MWCNT/TiO ${ }_{2}$ composites, pure adsorption experiments were performed under dark 
conditions and the results are shown graphically in Fig. 5. From Fig. 5, the level of reactive black-B adsorption by Pd-MWCNT/ $\mathrm{TiO}_{2}$ shows better adsorption ability than $\mathrm{MWCNT} / \mathrm{TiO}_{2}$ composite (from $-30 \mathrm{~min}$ to $0 \mathrm{~min}$ ).

Photocatalytic activities: After irradiation for $2 \mathrm{~h}$, both of the samples exhibit good degradation efficiency of reactive black-B solution. The degradation results of the two samples were shown in Fig. 4. From overall results shown in Fig. 4 the $\mathrm{Pd}-\mathrm{MWCNT} / \mathrm{TiO}_{2}$ catalyst showed better degradation ability not only in terms of its adsorption, but also its photocatalytic degradation. The result of recycle experiments were shown in Fig. 5, $46 \%$ of reactive black-B was degraded when Pd$\mathrm{MWCNT} / \mathrm{TiO}_{2}$ was used for the first time. After three times recycles, a small decrease of photocatalytic activity with $\mathrm{Pd}-\mathrm{MWCNT} / \mathrm{TiO}_{2}$ was found, $41 \%$ of reactive black-B was degraded in 150 min, respectively as shown in Fig. 4.
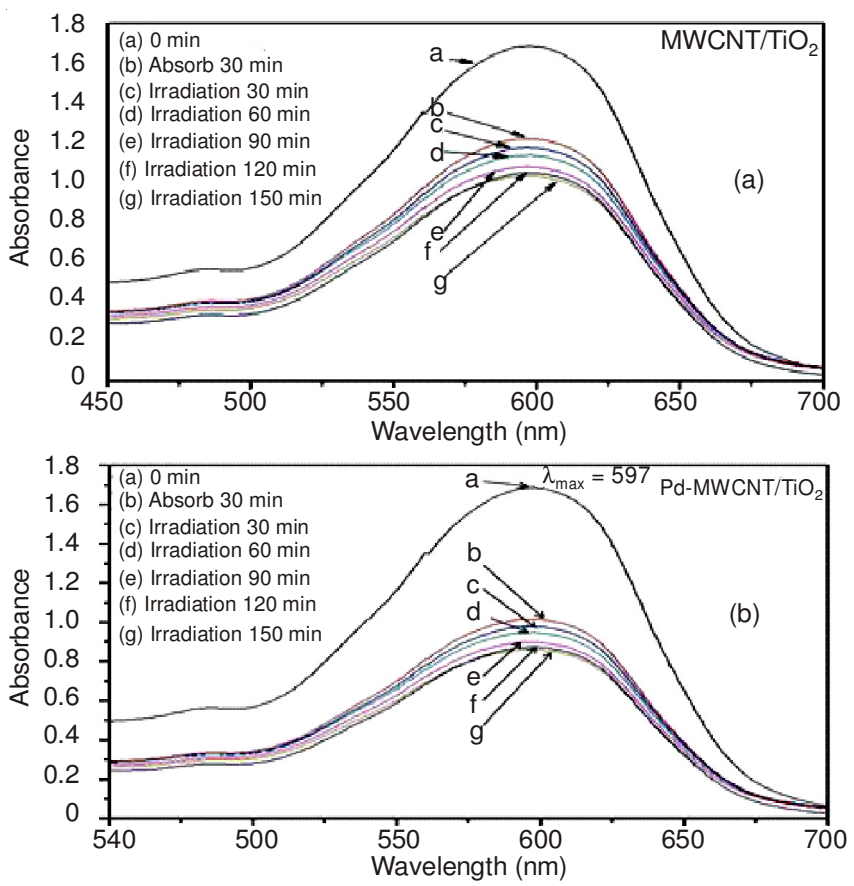

Fig. 4. Photodegradation of reactive black-B solution under visible light irradiation: (a) MWCNT/TiO ${ }_{2}$; (b) Pd-MWCNT/TiO 2

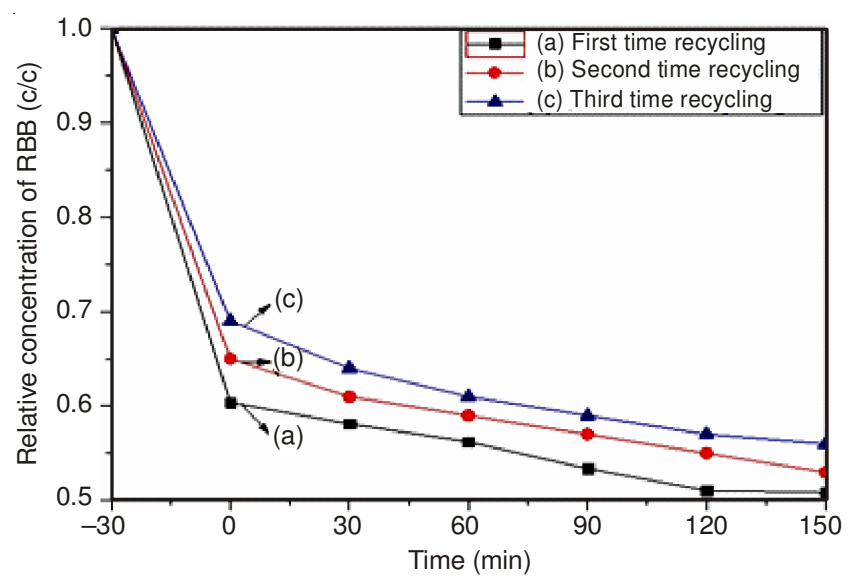

Fig. 5. Relative concentration of reactive black-B(c/cos $)$ under visible light irradiation; (a): first time recycle; (b): second time recycle; (c): third time recycle
Photo-degradation mechanism: The Pd-MWCNT/TiO composites have a narrower band gap and can increase the level of photo-degradation under both UV and visible light. This whole process is clearly described in Fig. 6.

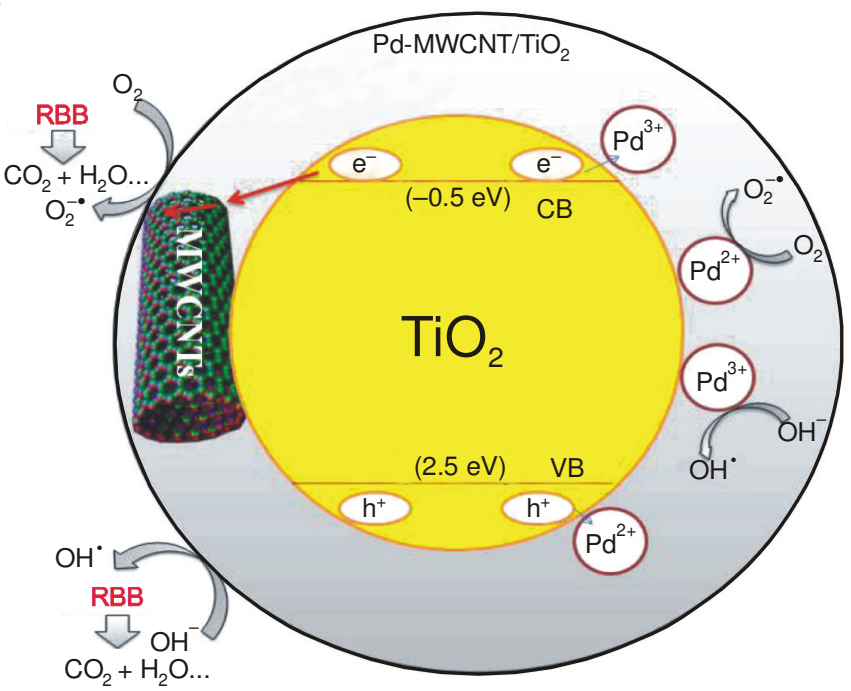

Fig. 6. Simple mechanism of degradation of reactive black-B by Pd$\mathrm{MWCNT} / \mathrm{TiO}_{2}$ composite

\section{Conclusion}

MWCNT/TiO 2 and Pd-MWCNT/TiO ${ }_{2}$ composites were synthesized by microwave assisted method. Compared with the pristine MWCNT, though the surface areas of MWCNT/ $\mathrm{TiO}_{2}$ and Pd-MWCNT/TiO 2 were greatly decreased, they showed good adsorption effects. Under visible light irradiation, reactive black-B, which is a typical standard dyestuff, was easily and efficiently degraded by the $\mathrm{Pd}-\mathrm{MWCNT} / \mathrm{TiO}_{2}$ composite. Meanwhile, sample Pd-MWCNT/TiO 2 showed better photocatalytic activity than $\mathrm{MWCNT} / \mathrm{TiO}_{2}$ sample. After the third time recycling, the sample still remains relative stable degradation efficiency of reactive black-B solutions.

\section{REFERENCES}

1. Z.D. Meng, L. Zhu and W.C. Oh, J. Ind. Eng. Chem., 18, 2004 (2012).

2. T. Ghosh, K.Y. Cho, K. Ullah, V. Nikam, C.Y. Park, Z.D. Meng and W.C. Oh, J. Ind. Eng. Chem., 19, 797 (2013).

3. G.-D. Zhu and W.H. Okamura, Chem. Rev., 95, 1877 (1995).

4. T. Ghosh and W.-C. Oh, J. Photocatal. Sci., 3, 17 (2012).

5. K. Ullah, L. Zhu, Z.-D. Meng, S. Ye, Q. Sun and W.-C. Oh, Chem. Eng. J., 231, 76 (2013). 